\title{
COMPONENT TEST FACILITIES FOR MARINE RENEWABLE ENERGY CONVERTERS
}

\author{
L Johanning, P R Thies and G H Smith, University of Exeter, UK
}

\section{SUMMARY}

This paper describes how the PRIMaRE group at University Exeter is engaging in the establishment of appropriate reliability methods suitable for application to marine renewable devices with a key area being the production of suitable failure rate data for the marine renewable energy industry. This activity seeks to mitigate uncertainties and cost implications associated with the reliability assessment of marine energy converters (MECs) due to an omnipresent lack of applicable failure rate data.

The capability of two facilities, namely i) the South Western Mooring Test Facility (SWMTF) and ii) the Dynamic Marine Component Test facility (DMaC), to perform specimen and accelerated component testing is discussed. A case study, using data from wave tank tests and numerical simulations performed for the SWMTF, serves to illustrate how evidence of component reliability under operational conditions could be provided.

\section{NOMENCLATURE}

$\begin{array}{ll}\mathrm{H}_{\mathrm{S}} & \text { significant wave height }[\mathrm{m}] \\ \mathrm{T} & \text { wave period [s] } \\ \mathrm{f} & \text { sample frequency }[\mathrm{Hz}] \\ \lambda_{\mathrm{P}} & \text { predicted failure rate }[1 / \mathrm{a}] \\ \lambda_{\mathrm{B}} & \text { base failure rate [1/a] } \\ \pi_{\mathrm{E}} & \text { environmental loading factor [-] } \\ \pi_{\mathrm{Q}} & \text { quality factor [-] } \\ \pi_{\mathrm{A}} & \text { application stress factor [-] } \\ \lambda_{\mathrm{EQUIP}} & \text { total equipment failure rate }[1 / \mathrm{a}] \\ \lambda_{\mathrm{g}} & \text { generic failure rate }[1 / \mathrm{a}]\end{array}$

Keywords: Reliability, Marine energy converters, Failure rate, component testing, accelerated test

\section{INTRODUCTION}

Marine energy technology is currently emerging from a research and development phase toward commercial deployment. Some devices have already reached a precommercial stage and in the UK, commercial-scale projects with a capacity of $57.5 \mathrm{MW}$ are being developed [1].

Prototype development and testing has largely focused on the demonstration of working principles, conversion efficiency and the survivability of devices. However, the viability of commercial marine energy projects will be driven by plant-performance indicators like reliability, availability and maintainability, as these will heavily influence project cost and revenue. Concise reliability assessments supported by extensive component testing form the basis for the commercial case and it is accepted that in order to ensure both survivability and availability a broad knowledge base of marine component's performance and failures needs to be established. Employing extensive testing in representative conditions is considered suitable [2] but so far sparsely applied in the marine energy industry.
The Peninsula Research Institute for Marine Renewable Energy (PRIMaRE) research group at the University Exeter is actively engaging in the establishment of failure rate data for the marine renewable energy industry. Two testing facilities, namely i) the South Western Mooring Test Facility (SWMTF) and ii) the Dynamic Marine Component Test facility (DMaC), allow to perform specimen and accelerated component testing for marine renewable energy components. Loads that are experienced in the field through testing at the SWMTF, or through information from device developers, can be used to accurately replicate load conditions for accelerated testing at the $\mathrm{DMaC}$ facility. The appeal of such testing is not only to obtain necessary data for marine energy applications but to reveal all potential failure modes and gain valuable insight into the physics of failure.

The paper is organised in four sections. It first briefly reviews existing and proposed marine component test facilities and gives some detail on facilities developed at the University of Exeter (section 2). Further, issues related to the reliability assessment of Marine energy converters (MEC), necessitating dedicated component testing, are discussed (section 3). The process of providing evidence of component reliability under operational conditions is exemplified with data from wave tank tests and numerical simulations performed for the SWMTF (section 4).

\section{MARINE COMPONENT TEST FACILITIES \\ 2.1 EXISTING AND PROPOSED MARINE COMPONENT TESTING}

A dedicated marine component test facility to collect reliability data especially for wave energy converters was suggested by Salter [3] and described later in more detailed [4], but was not realised since then. The design comprised test beds to operate rams, seals, belts and 
cables at their operational use conditions; conduct cavitation testing and expose components to marine fouling conditions to assess the effectiveness of coatings. The initiative was not pursued in this form, possibly due to the size and complexity of the test platform and the demand to share all failure and reliability information that would be obtained.

However, a more specific full-scale laboratory test rig was built by the Pelamis developers in order to test their hydraulic power take-off $[5,6]$. The power module of the Pelamis device was exercised by an externally mounted hydraulic actuation system (rated at 1MW) that replicated the heave and sway wave force and movement. The objectives of this test effort were mainly providing evidence of the power conversion efficiency, verifying the control algorithms, functional testing of the power module components, particularly seal performance and gaining experience to assemble and operate the power take-off. The intention was not to provoke failures by accelerated testing, but rather "(...) increase confidence in reliability before the first offshore test" [6].

Another test rig that aims to replicate wave profiles up to $3 \mathrm{~m}$ is a hydraulic linear mover, rated at $55 \mathrm{~kW}$ hydraulic power with a maximum force of $63.8 \mathrm{kN}$. It is designed to test the performance of power take-off systems [7] and was used to evaluate the conversion performance of a new device concept (Aegir Dynamo) employing a permanent magnet rotary generator under realistic, simulated wave force conditions [8].

A recent initiative to establish component testing for marine renewables is the Nautilus project proposed by NaREC. It aims to set up a $3 \mathrm{MW}$ full scale drive train test rig until March 2011 [9].

Testing efforts seem to be mainly concerned with the functionality and performance of the power take-off system assuming perhaps that other components can be understood from other areas of marine operations. However one must consider the particular problems imposed by there incorporation in a MEC. For example the mooring system will be exposed to unusual load time histories as part of the dynamic system.

Furthermore a tendency to demonstrate the reliability of systems and components is apparent in the testing approach undertaken by Pelamis, rather than accelerating the reliability test and inducing failures. While this is a suitable approach to convey confidence, it does not investigate the physical limits of the components (i.e. reliability limits). This disparity is highlighted by O'Connor [10], that in order to come to meaningful results in a cost- and time-effective way "(...) we must test to cause failures, not test to demonstrate successful achievement".

Offshore moorings are routinely fatigue-tested. This includes specific operational conditions like the tensiontorsion fatigue behaviour of wire ropes [11]. Detailed examination and tensile testing for internal wear [12] or the testing of damaged mooring ropes to determine their damage-tolerance behaviour [13] are also conducted.

These tests apply tension testing to determine the fatigue life behaviour, but do not consider the particularities of wave energy converters. The PRIMaRE test facilities described in the following are aiming to replicate the dynamic movements of mooring assemblies and other components/sub-systems in order to assess the reliability implications of operational field loads.

\subsection{SOUTH WESTERN MOORING TEST FACILITY (SWMTF)}

The SWMTF is a world first mooring load and response test facility, at large scale in real sea condition. It comprises a generic $2 \mathrm{t}$ buoy (see Figure 1), installed in Falmouth Bay and instrumented to gather data relating to the response of the buoy and the mooring line loads due to external loads [14] The influences; wave action, tidal currents, wind blown surface currents (of particular interest is the combined wave and current effects) and wind are being measured by the following instrumentation:

- On the bouy:

o Six degree motion measurement system

o Differential Global Positioning System (DGPS)

o Structural stress measurements

o Directional wind data on buoy

- Mooring system:

o Tri-axis top-end load cell

o In-line load cells

o Anchor point load cells

o Mid-line load cells

- Environmental condition monitoring:

o Multiple acoustic Doppler systems for waves/current (ADCPs)

o Onshore weather station

o Water quality measurements

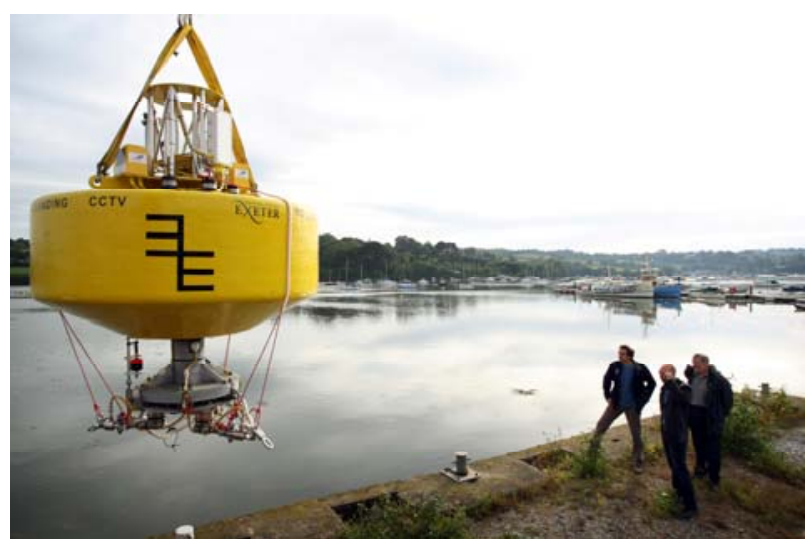

Figure 1 Launch of Mooring test buoy 
Processing of the data will allow a detailed analysis of the effectiveness of each mooring system at holding the buoy on station in a variety of conditions and will provide a thorough understanding of the loads imposed on the system.

\subsection{DYNAMIC MARINE COMPONENT TEST FACILITY (DMaC)}

The Dynamic Marine Component Test facility (DMaC) will provide the ability to the group to perform accelerated component testing. Whilst the SWMTF provides the ability to perform component testing in a realistic environment, including observation by ROV, the outcomes from these nearshore tests can be replicated at an accelerated manner in the DMac to improve performance and develop suitable components for the marine offshore industry.

The DMaC comprises the typical sub-systems of a conventional test rig:

- Force transmission - The subsystem that directly acts on the specimen/component.

- Drive/Actuation - in order to transmit the forces necessary for component deformation the point of force transmission needs to be actuated; this is achieved with a servo-hydraulic system.

- Control - the drive has to be controlled for a systematic deformation of the specimen.

- $\quad$ Response structure - The actuated forces need to be balanced with a structural frame.

- Measuring instruments - To control the actuation and acquire the specimen response all relevant parameters have to be measured.

- Data acquisition system

- Programmable Logic Controller (PLC) - To enable the control and comparison of set-point and actual value of the specimen response, the PLC must provide the set-points.

Beyond that, the proposed test rig will have unique features that are relevant to the component testing of components for marine renewable energy devices, allowing the dynamic testing in a wet environment. The three features allowing such advanced testing are:

- Constructing the test rig with a system to immerse the tested component

- Construction of a 3DOF moving headstock to allow replication of dynamic response as seen by component in realistic application

- A linear hydraulic actuator at the far end to provide necessary axial loading.

These features will allow a dynamic testing of components in large scale under controlled environment applying realistic motion characteristics. A 3DOF moving headstock is intended to be used that are commercially available and typically used in specific component reliability testing. Furthermore linear hydraulic actuators are also well established and applied within the field of material testing. The unique feature of this test rig is to combine these two test methods in dynamic loading under immersed conditions.

To be able to replicate the motion and forces experienced by a (MEC), or sub component, the test rig will provide a pulling and pushing force representative of wave motion (termed the $\mathrm{Z}$ actuator in the tailstock position) and a headstock with 3 degrees of freedom (namely pitch, roll and yaw); shown in principle in Figure 2.

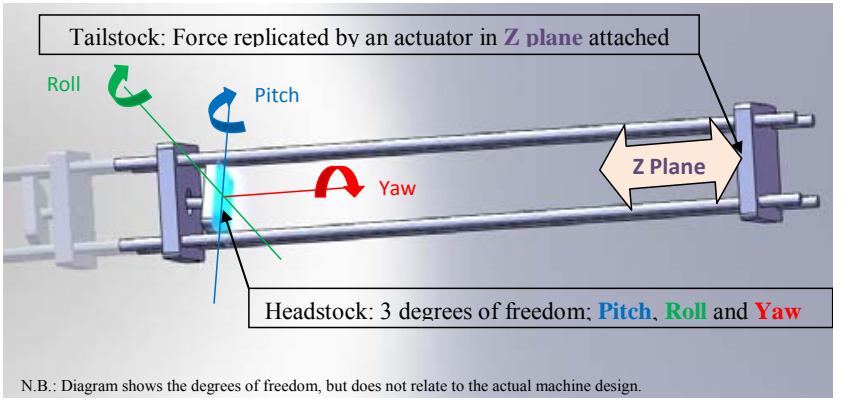

Figure 2: Functional illustration of the DMaC

The technical capability of the rig was specified as follows:

- Z Z actuator: 30t, capable to replicate compound waves, e.g. sine waves of different frequencies superimposed; as defined by Table 1 .

- $\quad$ Test bed: $6 \mathrm{~m}$ working length

- Headstock Pitch: $+30^{\circ}$ to $-30^{\circ}$ in $2 \mathrm{sec}$

- Headstock Roll: $+30^{\circ}$ to $-30^{\circ}$ in $2 \mathrm{sec}$

- Headstock Yaw: continuously

- Headstock test bed: diameter of $600 \mathrm{~mm}$ with component mounting arrangement

Table 1: DMaC functional specification

\begin{tabular}{c|ccc|c}
\hline & Amplitude 1 & Frequency 1 & Amplitude 2 & Frequency 2 \\
\hline & {$[\mathrm{m}]$} & {$[\mathrm{Hz}]$} & {$[\mathrm{m}]$} & {$[\mathrm{Hz}]$} \\
\hline & 0.5 & 0.1 & & \\
\hline & 0.25 & 0.1 & 0.05 & 1 \\
\hline & 0.05 & 1 & & \\
\hline & 0.025 & 1 & 0.005 & $10 \mathrm{~Hz}$ \\
\hline
\end{tabular}

\section{RELIABILITY ASSESSMENT FOR MARINE ENERGY CONVERTERS}

\subsection{CLASSIFYING PERFORMANCE ASSESSMENT}

The performance assessment of a system regarding reliability, availability and maintainability (RAM) provides vital information for decisions on project investment, design alternatives, operations \& maintenance strategies and the identification of components and subsystems for further improvement. Efficient RAM analysis is a tool to reach low failure rates and long mean time between failures (MTBF) [15], i.e. to optimise the system reliability, maximise availability and ensure the viability of marine energy projects. 
In general, two approaches to determine system performance measures can be distinguished [16] (see Figure 3 ):

- Measurement-based techniques require measured data from prototypes or real systems (e.g. generated electricity or recorded failures) and use statistical inference techniques to estimate the general system performance.

- Model-based assessments require a system model that has to be established, specifying random variables and system characteristics in order to derive performance measures. They can be further classified into simulation and analytical methodologies.

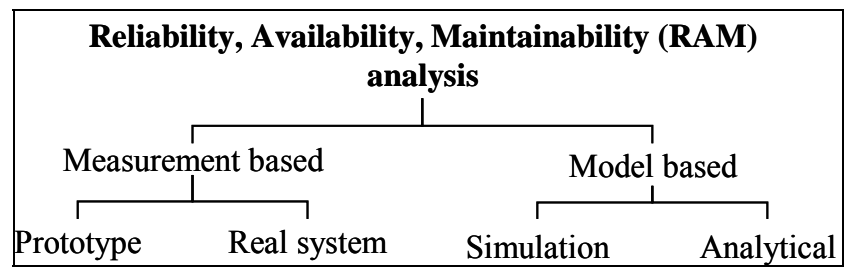

Figure 3: Classification of Reliability, Availability, Maintainability (RAM) analysis methods

Simulation methods utilise probabilistic distributions of component failure rates and repair regimes as input data and use numerical methods (e.g. Monte Carlo) to model the dynamic system behaviour with randomly generated discrete state events.

Analytical methods describe the system through several sets of equations and are either of the state space or the non-state space type. The state space describes the set of combinatory system states. A system comprising e.g. 10 components, where each component is in either of the defined states (e.g. functioning (0) or failed (1)) covers a space state of $10^{2}$ sets.

While the model based analysis provides well-known tools like reliability block diagrams (RBD) and fault tree analysis (FTA) it relies on the results of the more complex, more costly and time-consuming results of the measurement approach, where real-systems and/or prototypes are assessed.

For any reliability the quantity and quality of device information and knowledge of failure rate is crucial. Unfortunately the information available for marine energy devices is rather thin.

\subsection{LACK OF APPLICABLE FAILURE RATES}

The record of occurring field failures and their documentation (e.g. operating environment, maintenance schedule and failure modes) are key for conventional reliability assessments. Tavner et al. [17] have conducted a reliability analysis for the wind industry, using recorded data of 6,000 German and Danish wind turbines in a period as long as 11 years. This amount of data allows for statistically significant inferences. The early stage of the wave energy industry entails a scarcity of operational history.

Furthermore, the reliability data and experience gained during the few deployments are not publicly available, as they are seen as major competitive advantages over other developers [18]. This lack of data poses a serious problem for conventional reliability analysis. At this stage of the industry the twofold reliability approach of 'measure \& model' is heavily restricted to device modelling. The deployed devices are either not installed for a sufficient amount of time and/or number of devices to demonstrate meaningful levels of reliability, yet.

The qualification tests performed during the verification and validation process commonly conducted for MECs assure that the device meets its specifications and has the use characteristics stated. However, according to this kind of qualification tests do not provide any information on reliability parameters [19].

\subsection{ADAPTING KNOWN FAILURE RATES}

A common approach to overcome the scarcity of data would be to use available, often generic failure rate data of similar equipment and components. This seems reasonable as wave and tidal devices largely adopt existing technologies and materials developed for other industries. However, there has been very little activity of specific material development for marine renewable energy converters [20]. Due to significant environmental and operational differences known failure rates cannot be simply applied to MECs. They have to be adjusted to the dynamic behaviour requirements and associated response modes, possible new failure modes, environmental factors and operational loads and stresses [21]

The environmental influences and material phenomena which have to be considered for the operation of MECs are shown in Table 2.

Table 2: Environmental influences and material phenomena of marine energy converters

\begin{tabular}{l|l}
\hline $\begin{array}{c}\text { Environmental influences } \\
\text { (Wolfram, 2006) }\end{array}$ & \multicolumn{1}{c}{$\begin{array}{c}\text { Material phenomena } \\
\text { (Hudson, 1980) }\end{array}$} \\
\hline External water pressure & Corrosion \\
\hline Damp, saline atmosphere & Fatigue \\
\hline Temperature variations & Corrosion fatigue \\
\hline $\begin{array}{l}\text { Linear / rotational cyclic } \\
\text { motions and accelerations }\end{array}$ & Stray current corrosion \\
\hline Inaccessibility & Wear, fretting fatigue \\
\hline Human factors & Marine fouling \\
\hline & Impact loading, and fracture \\
\hline
\end{tabular}


3.3 (a) Reliability prediction methods

The Department of Defence produced a reliability prediction catalogue, MIL-HDBK-217F [22], which provides two prediction methods, the "parts count" - and the "parts stress" method, to account for different environmental and loading conditions.

The parts stress analysis prediction method is applicable to late design phases. Beside detailed stress analysis information it requires environmental conditions, quality applications, maximum ratings, complexity levels, temperature and other application-related factors. The basic calculation procedure to obtain failure rate predictions $\lambda_{\mathrm{P}}$ is the multiplication of a base failure rate $\lambda_{\mathrm{B}}$ (estimated from reliability tests under standardised laboratory conditions) with operational and environmental stress factors, so-called influence factors (Equation (1)). Typical environmental loading factors are shown in Table 3.

$$
\lambda_{P}=\lambda_{B} \cdot \pi_{Q} \cdot \pi_{E} \cdot \pi_{A} \cdots
$$

$\lambda_{\mathrm{P}}=$ predicted failure rate, $\lambda_{\mathrm{B}}=$ base failure rate,

$\pi_{\mathrm{E}}=$ environmental loading factor, and $\pi_{\mathrm{Q}}=$ quality factor,

$\pi_{\mathrm{A}}=$ application stress factor.

The parts count prediction method is applicable to early design phases where typically little information about the design and its specifications is known. Required information comprises generic part types, part quality levels and the equipment environment. To obtain the failure rate of equipment $\lambda_{\text {EQUIP }}$, a generic failure rate $\lambda_{\mathrm{g}}$ for each part is multiplied by a quality factor and summed up far all parts, see equation (2). The resulting failure rate expresses the failure of a series system. Hence, $\lambda_{\text {EQUIP }}$ is the upper boundary for systems incorporating redundancy. Equation (2) is applicable if the entire equipment is used in one particular environment. In the case of units that operate in different environments, the equation has to be applied separately to each individual unit.

$$
\lambda_{\text {EQUIP }}=\sum_{i=1}^{n} N_{i} \cdot\left(\lambda_{g} \cdot \pi_{Q}\right)_{i}
$$

Where $\lambda_{\mathrm{EQUIP}}=$ total equipment failure rate, $\lambda_{\mathrm{g}}=$ generic failure rate of i-th generic part, $\pi_{\mathrm{Q}}=$ quality factor of $\mathrm{i}$-th generic part, $\mathrm{N}_{\mathrm{i}}$ = quantity of $\mathrm{i}$-th generic part, $\mathrm{n}=$ number of different part categories

\section{3 (b) Limitations of reliability predictions}

The parts count method is a relatively simple prediction method which leads to more conservative estimation results than the parts stress method and is applicable in cases with limited information [23].

Yet, reliability predictions are subject to two major limitations, comp. e.g. [10,21].

- The first limitation is that the failure rate models are point estimates, based on available data. Therefore they are only valid for the assessed system and the environmental and operating conditions that prevailed during the data collection. Some extrapolation during model development is possible, but the inherently empirical nature of the failure rates has to be kept in mind. Furthermore, even if the data is used for reliability predictions in a similar operating environment, the variation due to different system applications can be significant.

- The second limitation is the dynamic industrial development of new machinery and processes, impeding reliability predictions. Assessments that are based on past data ignore any reliability improvement that might have taken place. Thus, past data for future reliability predictions tend to result in more pessimistic failure rates and need to be treated with scepticism.

Hence “(...) a reliability prediction should never be assumed to represent the expected field reliability as measured by the user" ([21], 3-2).

Table 3: Part stress analysis - Environmental loading factors

\begin{tabular}{lcl}
\hline Environment & $\begin{array}{c}\text { Factor } \\
\pi_{\mathrm{E}}\end{array}$ & \multicolumn{1}{c}{ Description } \\
\hline $\begin{array}{l}\text { Ground, } \\
\text { benign }\end{array}$ & 0.38 & $\begin{array}{l}\text { Nonmobile, laboratory } \\
\text { environment, Readily accessible } \\
\text { to maintenance }\end{array}$ \\
\hline Ground, fixed & 2.5 & $\begin{array}{l}\text { Conditions less than ideal, e.g. } \\
\text { unheated buildings }\end{array}$ \\
\hline $\begin{array}{l}\text { Ground, } \\
\text { mobile }\end{array}$ & 4.2 & $\begin{array}{l}\text { Equipment on wheeled or tracked } \\
\text { vehicles }\end{array}$ \\
\hline $\begin{array}{l}\text { Naval, } \\
\text { sheltered }\end{array}$ & 4.0 & $\begin{array}{l}\text { Sheltered / below deck } \\
\text { conditions, weather protected }\end{array}$ \\
\hline $\begin{array}{l}\text { Naval, } \\
\text { unsheltered }\end{array}$ & 5.7 & $\begin{array}{l}\text { Nonprotected surface, shipborne } \\
\text { equipment exposed to weather } \\
\text { conditions }\end{array}$ \\
\hline $\begin{array}{l}\text { Naval, } \\
\text { undersea, } \\
\text { unsheltered }\end{array}$ & 6.3 & Equipment immersed in salt water \\
\hline $\begin{array}{l}\text { Naval, } \\
\text { submarine }\end{array}$ & 4.0 & Equipment in submarines \\
\hline $\begin{array}{l}\text { Naval, } \\
\text { hydrofoil }\end{array}$ & 5.9 & Equipment in a hydrofoil vessel \\
\hline
\end{tabular}

Source: based on [21], 5.1.1-3 ff.

\subsection{UNCERTAINTIES AND IMPLICATIONS}

COST

The reliability assessment of MECs is a challenging task due to an omnipresent lack of applicable failure rate data. The presented approaches allow accounting for environmental and operational differences but are rather crude due to scarce information of component loads and behaviour; missing informed and proven adjustment factors for the marine renewable application. Such crude adjustments might lead to rather unfavourable pessimistic reliability predictions with high uncertainties. Large prediction uncertainties for reliability are known to be caused by the combined occurrence of new 
components, different operating environments and higher stresses [24], as it is the case in the marine renewable application.

The potential effect of such uncertainties has been shown in [25], who estimated the system reliability of a notional WEC configuration (assuming one year operation in absence of maintenance); using Reliability Block diagrams and adjusting available failure rate data. The possible consequence of an assumed $\pm 40 \%$ variability of the used structural failure rates on the overall reliability of the system is shown in Figure 4.

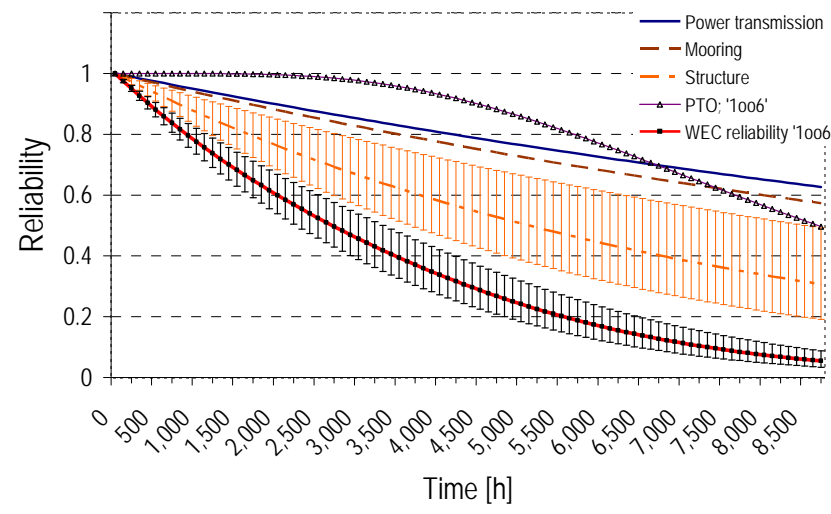

Figure 4: System reliability of a notional WEC and the effect of $\pm 40 \%$ variability of the structural failure rate.

Large reliability prediction uncertainties have a direct effect on costs as higher design safety factors are needed. These often vague and subjective factors of safety are dubbed by [4] as "factors of ignorance" which lead directly to "factors of waste", i.e. higher cost due to over engineered devices.

In that context, there is a need to assess and quantify the actual load and stress distributions (i.e. resulting failure rates) that can be expected from devices in operation. By means of dedicated component testing, occurring failure modes can be investigated, the design can be optimised and ultimately more informed failure rate probabilities can be established considering the expected operational and environmental loads.

\section{COMPONENT TESTING}

Reliability testing and demonstration are an integral part of the overall reliability programme of a project. While reliability testing aims to reveal any design weaknesses and tries to establish if the component/equipment under test meets the operational requirements; the demonstration of reliability shall also provide evidence that the component meets a specified reliability target under stated conditions [26].

Reliability testing is widely used in numerous industries to provide assurance of components and products. The general requirements and procedures are defined e.g. in the British Standard BS 5760:2003 [27].
Industries that made extensive use of reliability testing are e.g. the automotive-, aviation-, offshore oil and gas-, mining- and the astronautic industry. In all such cases the reliability of systems had to be assured before operational deployment/product launch, or long term specifications (e.g. operational safety, fatigue life) had to be established with limited operational experiences. A detailed list of the range of reliability test applications can be found in [28].

Nelson et al. [29] demonstrated the accelerated degradation process of umbilical cables caused by the combined environmental effects of cyclic loading, marine environment and ultraviolet radiation.

\subsection{PRIORITY COMPONENT TESTING FOR MECS}

Given the complexity of MEC systems and the limited resources available it is important to target the test regarding two categories.

Firstly, a clear methodology must be established to identify and rank in importance the type of components that should be tested. Currently, there is no clear agreement which components are most critical, as there are numerous devices based on completely different working principles and energy conversion mechanisms. A technology convergence to a few standard converter types as experienced by the wind energy industry has not taken place, yet.

Secondly, the number of failure modes that must be considered is diverse, ranging from marine fouling to fatigue and the loading regimes (type and frequency) can be quite different from those normally experienced by the naval and offshore industries. MEC developments will also be subject to challenging issues such as small profit margins and remote operating conditions that have to be considered.

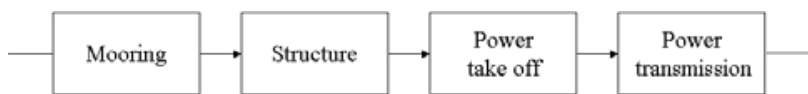

Figure 5: Generic sub-system block diagram for marine energy converters (MECs)

The general purpose of a MEC system is the generation of electricity. In spite of the wide variety of devices that have been proposed, the function of sub-systems for MECs is very similar [20]. Regarding the intended subsystem function, a generic WEC can be characterised by four different subsystems, as shown in the generic series block diagram in Figure 5:

- Mooring - in the case of near shore and offshore devices the moorings provide the station keeping of the device.

- Structure - it provides shelter for the power take-off machinery, maintains the system's level of buoyancy withstands applied loadings and 
acts as a reference point to the device movements.

- $\quad$ Power take-off (PTO) - this converts the device movements induced by the wave/tidal energy into electricity

- Power transmission - the electricity is transmitted to shore via the power transmission sub-system.

An earlier study commissioned by the Carbon Trust and carried out by Black \& Veatch [30] attempted to assess and prioritise marine component technologies based on three criteria:

- Contribution to device costs

- Cost reduction potential

- Unlikelihood that cost reductions are realised in other industries

The study identified several key components for further research and testing which should contribute to make MECs more viable. The findings are grouped into subsystem categories (see Table 4), covering structural materials, powertrain and mooring components. As this gives an indication on which area of sub-systems and components to focus for testing, the screening is limited to the three criteria mentioned above.

A prioritisation from a reliability point of view would have to take into account the failure probability, the consequence (cost) of failure as well as the O\&M characteristics of components and sub-systems, which are likely to have considerable effect on the overall cost of energy. Bedard et al [31], e.g. estimate for a $100 \mathrm{MW}$ commercial wave farm, that as much as $40 \%$ of the cost of electricity is incurred by O\&M activities.

Table 4: Prioritised wave energy and tidal stream component technologies [29]

\begin{tabular}{lll}
\hline & Sub-system & Component \\
\hline \multirow{4}{*}{$\begin{array}{l}\text { Wave } \\
\text { energy }\end{array}$} & $\begin{array}{l}\text { Structural } \\
\text { Materials }\end{array}$ & $\begin{array}{l}\text { Floats and device body, } \\
\text { Offshore substation platform }\end{array}$ \\
\cline { 2 - 3 } & Powertrain & $\begin{array}{l}\text { Generator, } \\
\text { Power Converter (AC/DC/AC) }\end{array}$ \\
\cline { 2 - 3 } & Mooring & $\begin{array}{l}\text { Mooring tethers, Anchors, Device } \\
\text { connection }\end{array}$ \\
\hline & & \\
\hline \multirow{4}{*}{ Tidal } \\
stream & Rotor & Rotors \\
\cline { 2 - 3 } & Structural & Off-shore Substation Platform \\
\cline { 2 - 3 } & Powertrain & $\begin{array}{l}\text { Gearbox, generators, associated } \\
\text { equipment }\end{array}$ \\
\cline { 2 - 3 } & Mooring & Mooring components \\
\hline
\end{tabular}

A possibility to conduct such a prioritisation from a reliability perspective is the qualitative risk ranking methodology proposed by Bittencourt [32]. It rates possible incidents according to their expected frequency and consequence, covering covers function, safety, environment, operation and assets as impact areas and rates each on a scale from 1 (low) to 5 (high). Such a risk matrix approach is a useful tool to identify those components of a (prototype) device which lend themselves to dedicated testing.

For the purpose of this paper an approach to test mooring components for wave energy devices is described. Mooring assemblies are essential part of all offshore marine energy devices and failures have large consequences both from a power production (revenue) perspective but also safety from a safety point of view, should the device break free. Within a large array this could have even greater consequences than for a single device. Such a disastrous failure due to a broken load cell is e.g. reported in [33]. The offshore industry could mitigate these risks by extensive safety factors, redundancy and early, regular replacements.

\subsection{TEST PROCEDURE}

The process of providing evidence of system/component reliability under operational conditions can be divided into four subsequent steps [34]:

1. Measuring realistic load data

2. Identify representative loading regimes

3. Testing a (representative) sample on a laboratory test rig

4. Root cause analysis and statistical evaluation of test results

Ideally, realistic load data is of course measured in the field, e.g. the loads experienced by the components of a prototype device or sub-system. In the case of mooring configurations such measurements will be possible at the SWMTF, which is to be installed by the Peninsula Research Institute for Marine Renewable Energy (PRIMaRE) in Falmouth Bay. The tension loads will be measured with a triaxial load-cell and can be correlated to the buoy movement and the wave climate.

\subsection{CASE STUDY}

To provide an example here, data from tests conducted at the MARINTEK institute in Trondheim, Norway are used for a case study. Generic floating Oscillating Water column devices (OWCs) have been tested at 1/20 scale. The devices were instrumented with mooring line load cells, optical motion tracker and accelerometers. Different wave and current test conditions were applied to the device, while motion (6 DOF) and mooring forces were monitored $[35,36]$.

A 3-leg configuration with a $120^{\circ}$ spread was chosen to for the mooring of the generic OWC.

The time series in Error! Reference source not found.a show an excerpt of the obtained load signal for one of the mooring lines. This specific test run simulated a wave climate with a significant wave height $\mathrm{H}_{\mathrm{S}}=3.5 \mathrm{~m}$ and wave period $\mathrm{T}=8.0 \mathrm{~s}$. The test was run for $120 \mathrm{~min}$, with a data sample frequency $\mathrm{f}=20 \mathrm{~Hz}$. All results have been presented by their full scale values. 


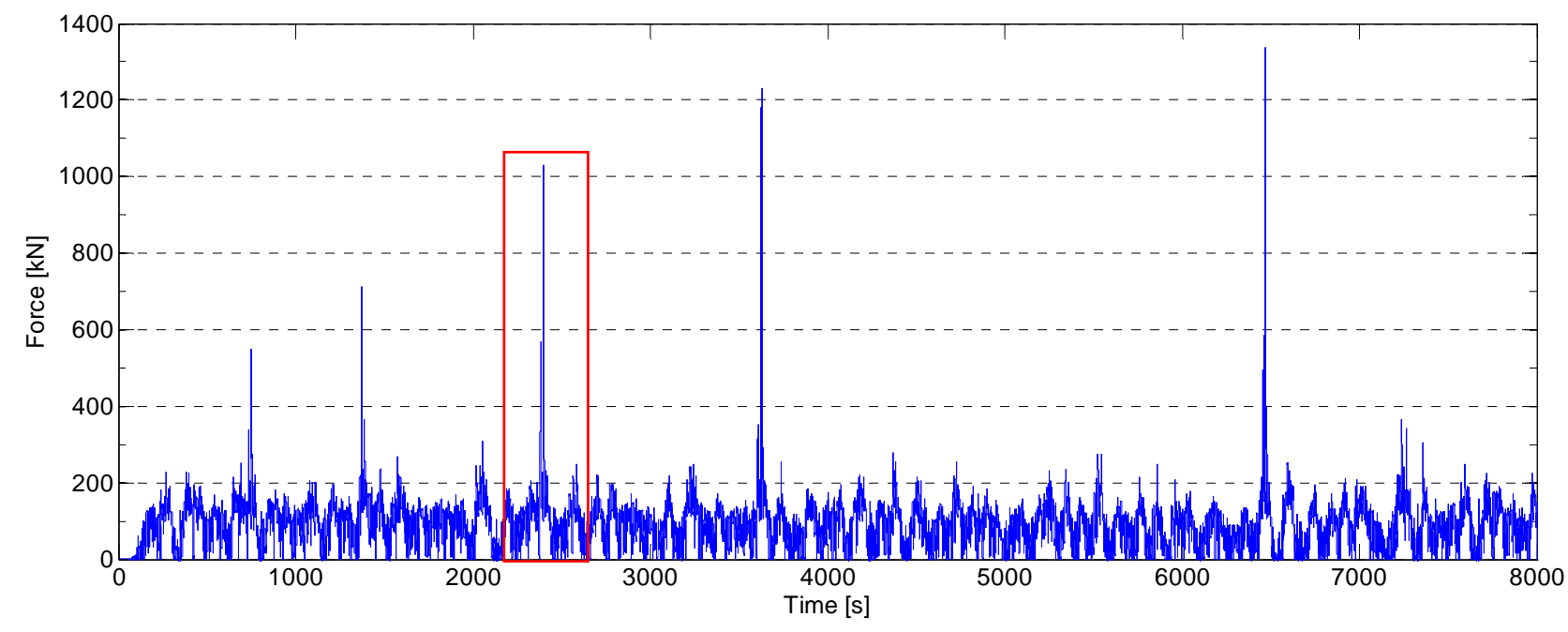

(a)

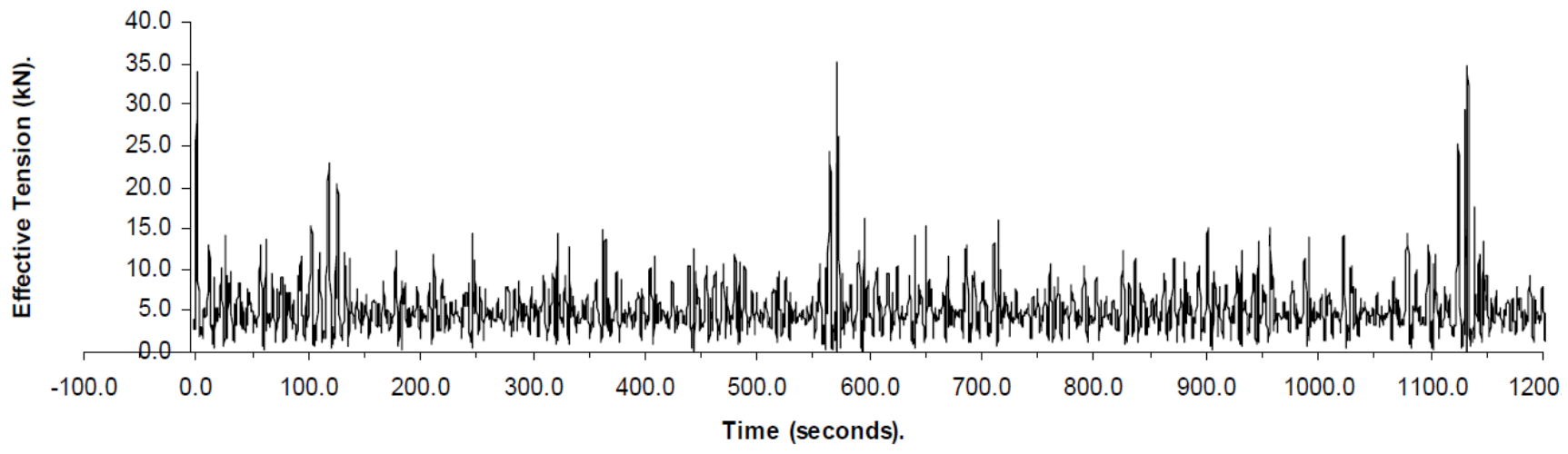

(b)

Figure 6a,b: (a) Raw signal of line tension force $\mathrm{F}$ [kN] for test tank experiment (full scale dimensions); (b) Predicted time series of effective fairlead tension $\left[\mathrm{kN}\right.$ ] for the $\mathrm{SWMTF}$ at $\mathrm{H}_{\mathrm{S}}=3.5 \mathrm{~m}, \mathrm{~T}_{\mathrm{P}}=7 \mathrm{~s}$ simulated using OraFlex.
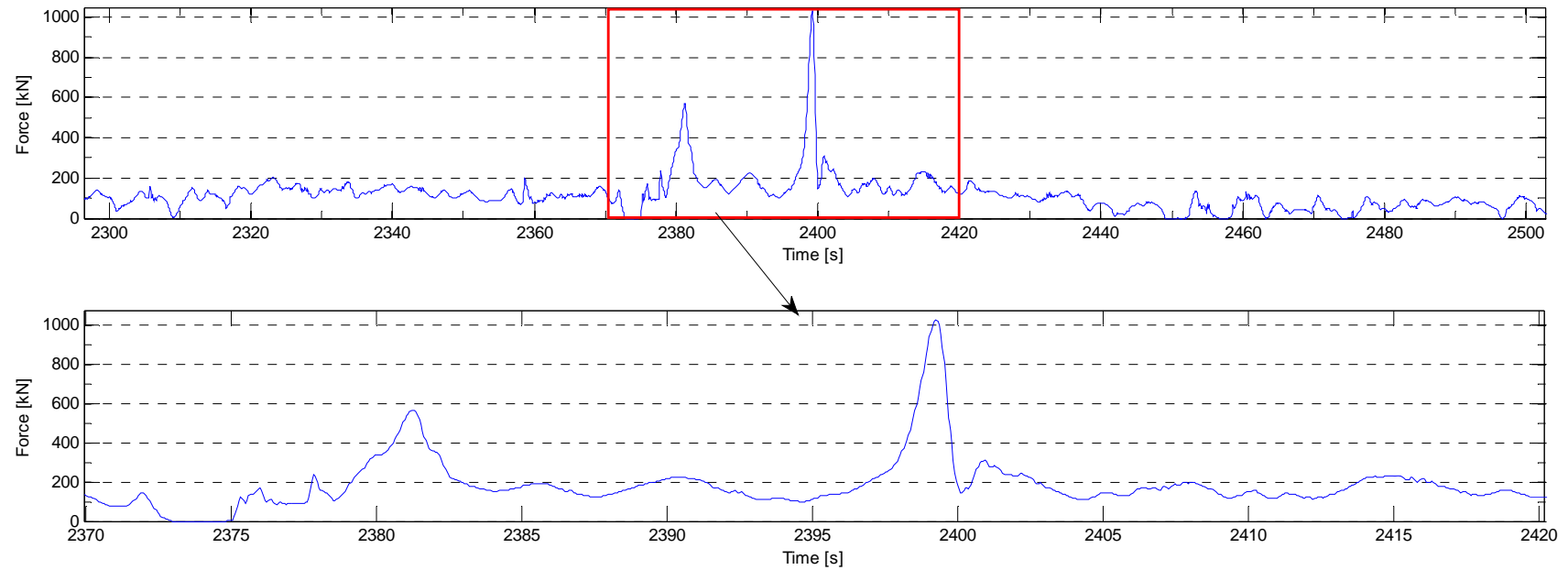

Figure 7: Magnification of section from experimental test tank signal identifying peak loads. 


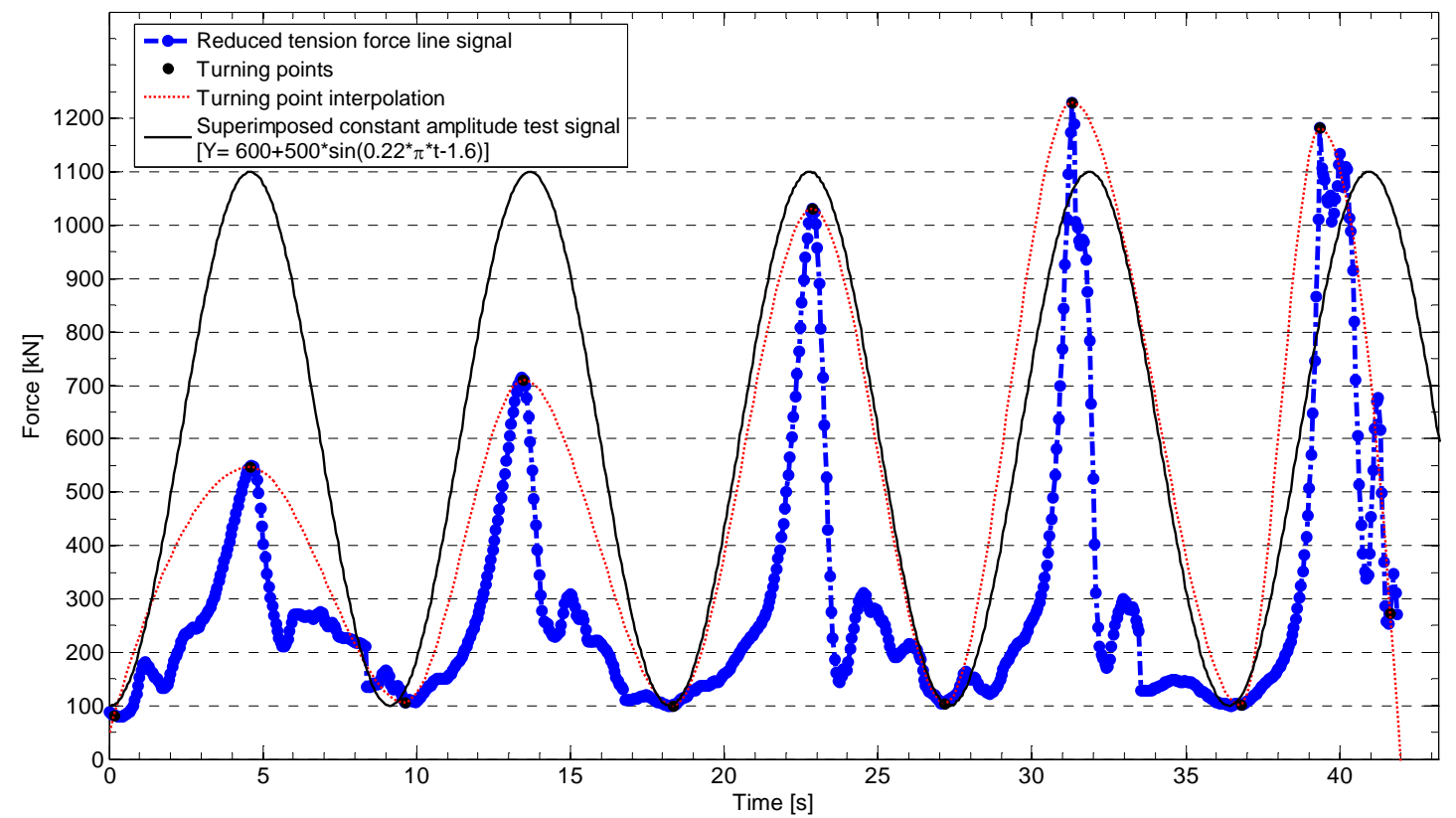

Figure 8: Distilled mooring tension load signal $[\mathrm{kN}]$, turning points and indicative test cycle regime

The signal shows a fluctuating tension force with occasional spikes. These spikes are due to occurring snatch loads of the mooring line, caused by a sudden acceleration of the OWC. While most of the load fluctuates around $\mathrm{F}=200 \mathrm{kN}$, the snatching induces much higher loads of $\mathrm{F}>1000 \mathrm{kN}$.

This set of tank test data compares very well with simulation results that have been carried out using the commercial software package OrcaFlex [37] to predict the effective tension for a mooring leg at the SWMTF site (Figure 6b). For the numerical load analysis a 3-leg mooring configuration was applied with a spread of $120^{\circ}$ between each leg, was similar to the one used in the test tank.

The site was modelled using predicted wave data of wave height up to $\mathrm{Hs}=3.5 \mathrm{~m}$, and wave period, $\mathrm{Tp}=7 \mathrm{~s}$. Wind and current loading on the buoy have been calculated using estimated values for wind speed of $12 \mathrm{~m} / \mathrm{s}$ and a current velocity of $0.8 \mathrm{~m} / \mathrm{s}$. A water depth of $32 \mathrm{~m}$ was used in the analysis.

Each wave condition was simulated over a period of 1,200 s to identify if special load events appear more frequently. The variation in effective tension of the fairlead for the extreme case $(\mathrm{Hs}=3.5 \mathrm{~m}, \mathrm{Tp}=7 \mathrm{~s})$ is shown in the lower graph of Error! Reference source not found. (a).

Whilst moderate peak tensions (not exceeding $15 \mathrm{kN}$ ) can be mostly observed on the graph, three extreme peak loadings can be observed. The first peak occurs shortly after the build-up period of the simulation, essentially as soon as the motion of the buoy first causes the mooring line to become taut. The following peaks appear roughly at 575 second intervals, again as the mooring line becomes completely stretched in a pseudo periodic motion. These three peaks are clearly identifiable in the time history of all simulations performed.

Since the simulated load conditions for the SWMTF and the tank test results compare well regarding the occurring extreme peaks, the experimental data is used for the remainder of the paper to illustrate the generation of a suitable test load regime.

\section{3 (a) Identifying representative loading regimes}

Once representative load data is established, the most severe load cycles can be used to derive a loading regime for the accelerated testing (see Figure 6and 7).

Heuler and Klätscke [38] describe how standardised load spectra and load-time histories have been generated and used in various industries to assess the fatigue behaviour of structures and components when simple constant amplitude assumptions/data do not provide a sufficient level of confidence. This is particular the case if the load spectra significantly differs in amplitude and mean-stress variations compared to constant amplitude loading and in the case of multiaxial loading. As a result, a number of standardised load-time histories (SLH) are in use, which cover the representative fraction of the expected inservice spectrum to facilitate fatigue analysis. Standardised load sequences and load time histories have been proposed for aircrafts (TWIST, FALSTAFF), helicopters (HELIX), cars (CARLOS), wind turbine blades (WISPER/WISPERX) and offshore structures (WASH). Particularly the automotive industry extensively applies SLH's to assess the performance of wheel suspension systems. 


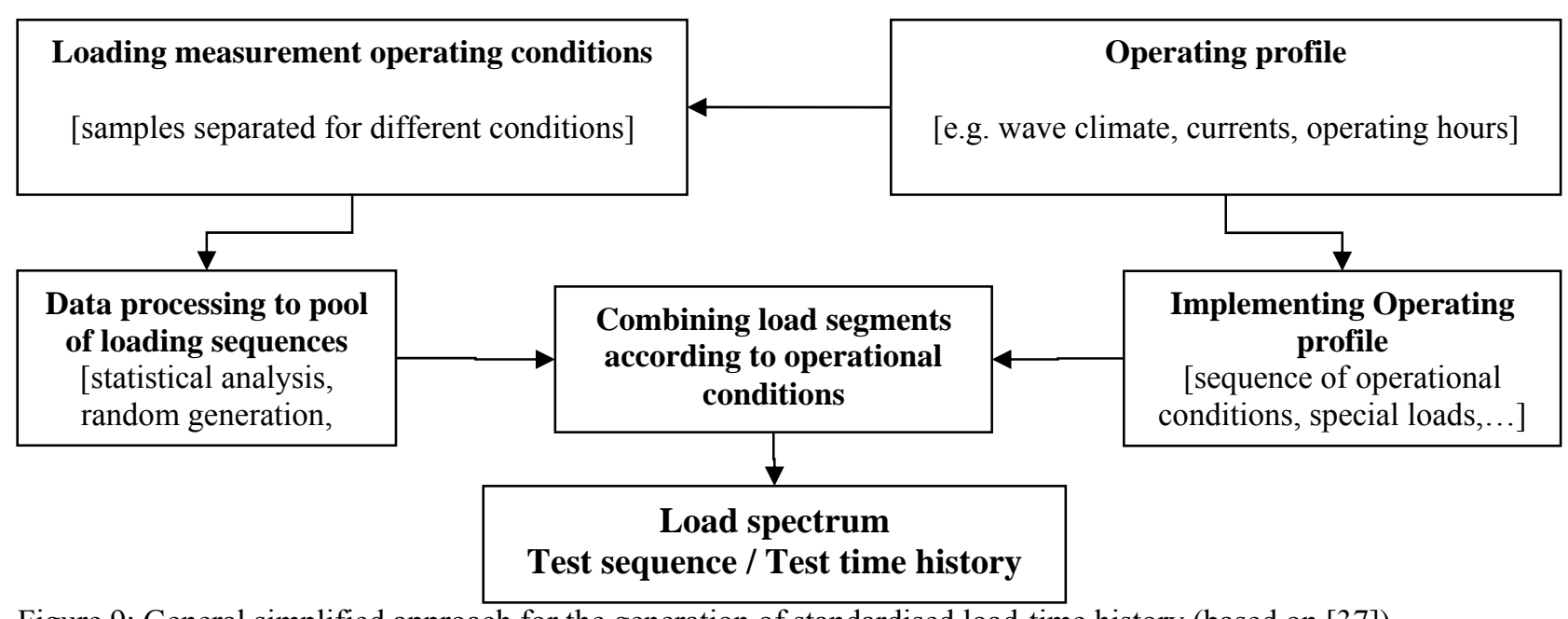

Figure 9: General simplified approach for the generation of standardised load-time history (based on [37])

Such load-time sequences are established through field measurement (e.g. strain gauges, accelerometers) which are then synthesised to representative test loads. The general procedure is depicted in Figure 9, while the detailed procedures are specified in [37,39].

\section{3 (b) Testing on a test rig}

In order to complete the testing within justifiable time and cost budgets, the load signal is usually reduced and if possible accelerated.

Accelerated testing cycles the items under more severe stresses compared to the expected normal operation which leads to earlier failures and hence reduced testing periods. It is important, that the failure mode of normal operation and accelerated conditions stays the same [40].

Escobar and Meeker [41] distinguish four general possibilities that can be applied to accelerate reliability tests, by increasing the following characteristics:

- Use rate of the component, e.g. increased load cycle frequency

- Radiation exposure intensity, e.g. increased UV radiation

- Aging rate of the component, e.g. increasing the chemical degradation process through higher levels of humidity

- Test stress levels, e.g. increased load force ranges compared to normal operating conditions

In the present case study the use rate of the mooring assembly can be accelerated when the original load signal is distilled to the most severe load cycles (tensile load force in excess of $600 \mathrm{kN}$ ). This distilled line tension signal, the corresponding turning points and a possible test rig signal (interpolation between turning points) are shown in Error! Reference source not found.
The use of such a test signal could replicate the most severe loads of a $2 \mathrm{~h}$ test in less than a minute of laboratory test time and could hence simulate one year operational loads under the assumed conditions in approx. $60 \mathrm{~h}$ of continuous testing.

\section{3 (c) Root cause analysis and statistical evaluation of test results}

Both parametric and non-parametric models can be used to derive a statistical model from the test results which shall give an indication of failure rates and lifetimes under normal operational use. Rausand and Høland [42] describe a range of models applicable to different acceleration designs

However, for statistically significant results numerous components need to be tested, so in early design stages is more cost efficient to test one component under accelerated conditions, investigate the root cause of the failure and aim for a design improvement. The improved component can then be retested [10].

\section{CONCLUSIONS}

This paper has given an account of the issues related to the reliability assessment of marine energy components and systems. A brief review of existing marine component test facilities has shown a strong emphasis in the evaluation and simulation of power take off capabilities. Dedicated reliability testing of components under operational conditions, using e.g. accelerated reliability testing, does not seem widely adopted in the marine renewable industry, yet. As a result, the reliability assessment of MECs is burdened with high uncertainties which have cost implications due to higher safety factors requirements to avoid early field failures.

However, component reliability testing is commonly used in other industries to evaluate field failure rates 
more accurately and reveal possible failure modes/design weaknesses.

The capability of two facilities developed by the research group has been described. Loads that are experienced in the field through prototype testing, or through information from MEC developers, could be used to accurately replicate load conditions for accelerated testing and ultimately evaluate the operational failure rates of component.

Adopting such a testing approach might be time- and capital expensive, but provides a possibility to accurately assess and demonstrate the component reliability of MECs before they are deployed in the field where failures would be prohibitively high, in particular in the case of array configuration with numerous devices.

For the marine renewable energy sector to emerge successfully from the research and development phase toward commercial-scale deployment, confidence in the economic operation of large arrays is fundamental. Properly specifying the reliability state of the device to established accuracy is a key element and the testing of marine components must be an essential goal.

\section{ACKNOWLEDGEMENTS}

The authors would like to acknowledge the support of the South West Regional Development Agency for its support through the PRIMaRE institution. They would also like to acknowledge the European Community's Sixth Framework Programme HYDRALAB III, Contract no. 022441 (RII3). The second author would like to acknowledge the funding support from the Engineering and Physical Sciences Research Council (EPSRC) under the SUPERGEN Marine Doctoral Programme. Thanks also to Orcina for provision of their Orcaflex software

\section{REFERENCES}

[1] ENTEC, 'UK, Marine renewable energy. State of the industry report', Technical report British Wind Energy Association (BWEA), October 2009.

[2] MUELlER, M., WALLACE, R., 'Enabling science and technology for marine renewable energy', Energy Policy, Vol. 36, pp. 4376-4382, 2008.

[3] SALTER, S.H., 'Research requirements for fourth generation wave energy devices', in: European Community, Results from the work of the European Thematic Network on Wave Energy (WaveNet), pp.194-224 2003.
[4] SALTER, S.H., 'Proposals for a component and sub-assembly test platform to collect statistical reliability data for wave energy', Proc. of the Fourth European Wave Energy Conference, Cork, 2003.

[5] HENDERSON, R., 'Design, simulation, and testing of a novel hydraulic power take-off system for the Pelamis wave energy converter', In: Renewable Energy, Vol. 31, pp. 271-283, 2006.

[6] YEMM, R. Pelamis WEC - Full-scale joint system test', DTI report [V/06/00191/00/00/REP, DTI URN 03/1435], 2003.

[7] OCEAN NAVITAS, Hydraulic Linear Wave Simulator, http://www.oceannavitas.com/technology/wave_si mulator.html, 2007, (accessed on 26/01/10).

[8] AL-HABAIBEH, A., SU, D., MCCAGUE, J., KNIGHT, A., 'An innovative approach for energy generation from waves', In: Energy Conversion and Management (article in press), 2010

[9] NAREC, 'Project Nautilus - A dedicated drive train test rig for the marine renewables industry', http://www.narec.co.uk/cmsfiles/ENR1021\%20Na utilus\%20Flyer.pdf, 2009, (accessed on 26/01/10).

[10] O'CONNOR, P.D.T. 'Practical Reliability Engineering', (4th ed.), Chichester: Wiley, 2002.

[11] RIDGE, I.M.L., 'Tension-torsion fatigue behaviour of wire ropes in offshore moorings', In: Ocean Engineering, Vol. 36, pp. 650-660, 2009.

[12] TENSION TECHNOLOGY INTERNATIONAL [TTI], Durability of polyester ropes, MMS Final project report, Ref.: TTI-SJB-2005-321, 2006.

[13] WILLIAMS, J. MIYASE, A., LI, D.I., WANG, S. 'Small-scale testing of damaged synthetic fiber mooring ropes', In: Proc. Offshore Technology Conference [OTC 14308], Houston, Texas U.S.A., 6-9 May 2002.

[14] JOHANNING, L., SPARGO, A., PARISH D.,' Large scale mooring test facility - A technical note', Proc. of $2^{\text {nd }}$ Int. conference on Ocean Energy (ICOE), Brest, France, 15 - 17 October 2008 .

[15] SHARMA, R. K., KUMAR, S., 'Performance modeling in critical engineering systems using RAM analysis', Reliability Engineering and System Safety, Vol. 93, 891-897, 2008. 
[16] SATHAYE, A., RAMANI, s., TRIVEDI, K.S. 'Availability models in practice', Proc. of International Workshop on Fault-Tolerant Control and Computing (FTCC-1), 2000.

[17] TAVNER, P. XIANG, J., SPINATO, F. 'Reliability Analysis for Wind Turbines', Wind Energy, Vol. 10, pp. 1-18, 2007.

[18]FLINN, J., BITTENCOURT, C. 'Reliability estimation method for wave and tidal energy converters', Proc. 2nd International Conference on Ocean Energy (ICOE), Brest, France 15th -17 th October 2008.

\section{[19]CONFEDERATION}

OF EUROPEAN ENVIRONMENTAL ENGINEERING SOCIETIES (CEEES), 'The different type of tests and their impact on product reliability', Technical advisory board Reliability and EES, 2009.

[20] COURT, S.A. 'Materials UK energy review 2008 - The mapping of materials supply chains in the UK's power generation sector', Technical report by the National Metals Technology Centre (NAMTEC). Available at: http://www.matuk.co.uk, 2008.

[21] WOLFRAM, J. 'On assessing the reliability and availability of marine energy converters', Proc. Institution of Mechanical Engineers [IMechE] Vol. 220, pp. 55-68, 2006.

[22]DEPARTMENT OF DEFENSE (DOD), Reliability prediction of electronic equipment MIL-HDBK 217-F, 1991.

[23] VINTR, M. 'Reliability assessment for components of complex mechanisms and machines', Proc. 12th World Congr. Mechanism Machine Science (IFToMM), [17-21 June 2007, Besancon, France., Eds. J.-P. Merlet, M. Dahan]. 2007.

[24] O'CONNOR, P.D.T. 'Quantifying uncertainty in reliability and safety studies', Microelectronic Reliability, Vol. 35, pp. 1347-1356, 1995.

[25] THIES, P.R., FLINN, J., ASMITH, G.H., 'Is it a showstopper? Reliability assessment and criticality analysis for wave energy converters', Proc. of 8th European Wave and Tidal Energy Conference (EWTEC), 2009.

[26] SANTHAMMA, K., S. et al. 'Reliability Testing and Demonstration', Reliability Engineering and System Safety Vol. 23, pp. 207-217, 1988.
[27]BS 5760-4:2003, 'Reliability of systems, equipment and components. Guide to the specification of dependability requirements', BSI, 2003.

[28]DHILLON, B.S., 'Reliability testing: Bibliography', Microelectronics Reliability, Vol. 32, 8, pp. 1115-1135, 1992.

[29]CARDENAS, N.O., MACHADO, I.F. GONCALVES, E., 'Cyclic loading and marine environment effects on the properties of HDPE umbilical cables', Journal of Material Science, Vol. 42, pp. 6935-6941, 2007.

[30]BLACK \& VEATCH, 'Key marine energy component technologies for cost reduction R\&D', Technical report, Carbon Trust, 2007.

[31]BEDARD, R. et al., 'Offshore wave power feasibility demonstration project', Final Summary report E21 EPRI WP 009 - US Rev2, Electric Power Research Institute (EPRI), 2005.

[32]BITTENCOURT, C. (2007). 'DNV OSS-312 Standardisation in the renewable marine energy sector' [Presentation held at 2nd International Seminar on Ocean Energy, 2007.

[33] CHRISTENSEN, L. et al., 'The Wave energy challenge - the wave dragon case.', Proc. PowerGen Europe, Milan, Italy, June 2005. Available at: http://www.wavedragon.net.]

[34] WELTIN, U., 'Reliability in Engineering Dynamics', Lecture notes Reliability Engineering, TUHH, available at: www.tuharburg.de/education/master/mechatronics/course.html

[35]BRYDEN, I., LINFOOT, B. 'Wave energy converters - project summary sheet HyIII-NTNU18', Hydralab III, 2009, available at: www.hydralab.eu

[36] ASHTON' I.G.C., JOHANNING, L.J., LINFOOT, B., 'Measurement of the effect of power absorption in the lee of a wave energy converter', Proc. of the ASME 28th International Conference on Ocean, Offshore and Arctic Engineering $31^{\text {st }}$ May - $5^{\text {th }}$ June, 2009.

[37] ORCINA, OrcaFlex software manual, Version 9.3a, www.orcina.com

[38]HEULER, P., KLÄTSCHKE, H., 'Generation and use of standardised load spectra and load-time histories', In: International Journal of Fatigue, Vol. 27, pp. 974-990, 2005. 
[39]KAM, J.C.P., 'Wave action standard history (wash) for fatigue testing offshore structures', In: Applied Ocean Research, Vol. 14, pp. 1-10, 1992.

[40] Lydersen, S., Rausand, M. 'A systematic approach to Accelerated Life Testing', Reliability Engineering, Vol. 18, 4, 1987.

[41]ESCOBAR, L.A., MEEKER, W.Q., 'A Review of Accelerated Test Models', Statistical Science Vol. 21, No. 4, pp. 552-577, 2006.

[42] RAUSAND, M., HØYLAND, A., ,System reliability theory. Models statistical methods and applications.' [2nd rev. ed., Wiley series in probability and statistics]. Hoboken: Wiley, 2004.

\section{AUTHORS BIOGRAPHY}

Dr. Lars Johanning is a Senior Lecturer in Renewable Energy at the College of Engineering, Mathematics and Science of Exeter. In his current position he is leading the PRIMaRE Marine Operation and Reliability group. Prior joining the Renewable Energy Group in September 2007 he was a researcher within the EPSRC sponsored Supergen Marine Consortium leading the researcher on mooring systems for floating marine energy converter with main focus on reliable station keeping.

Philipp R Thies is a $\mathrm{PhD}$ candidate at the University of Exeter. His research focuses on the reliability of marine energy converters. He holds a degree as Dipl.-Wi.-Ing. in 'Energy- and environmental management' with the University of Flensburg, Germany.

Dr. George H Smith is Professor in Renewable Energy at the College of Engineering, Mathematics and Science of Exeter. He led the Heriot-Watt University contribution to the Supergen Marine EPSRC research project. His principal personal contribution was related to wave analysis and resource assessment. He was also the work package leader for (i) Engineering guidance (ii) Moorings and Foundation and (iii) Full-scale testing. He led the development of the Wave Energy Device Protocol for the DTI Marine Renewable Development Fund and is now the lead academic at University of Exeter for the PRIMaRE research initiative. He is currently involved in two European Union marine energy research projects and is coinvestigator on an EPSRC funded project to investigate the possible use of wave ahead prediction. 